\title{
The Brazilian public healthcare system and its participation in medical training
}

\author{
Patricia Alves de Souza ${ }^{1^{*}}$, Marco Aurélio Da Ros ${ }^{2}$, Angélica Maria Bicudo Zeferino $^{1}$ \\ ${ }^{1}$ Universidade Estadual de Campinas, Campinas, Brasil; ${ }^{*}$ Corresponding Author: passpb@gmail.com \\ ${ }^{2}$ Universidade do Vale do Itajaí, Itajaí, Brasil
}

Received 6 June 2012; revised 30 June 2012; accepted 10 July 2012

\section{ABSTRACT}

Introduction: In Brazil, in a joint initiative of the Ministries of Health and of Education and Culture, the Program for the Promotion of Changes in Medical School Curricula (PROMED) was created, in order to give financial support to medical schools for the development and implementation of curricular changes to the medicine courses. Objective: To ascertain the influence of PROMED on the interaction between the Brazilian public healthcare system (SUS) and the universities. Method: Using the qualitative method by way of content analysis of the Bardin, interviews with 19 coordinators of the medicine courses which received financial support from PROMED were carried out and analyzed. Results: Subcategories which express the current relation between SUS and the universities were found: the need to train SUS professionals and the teaching staff involved, the lines of research directed toward SUS and partnership relations as part of the student learning process, the strengthening of SUS and the internal problems. Conclusions: Observing the needs of the relationship between SUS and the curricular changes it was noted that the public health services are of extreme importance as part of the training process of the medical student. Besides favoring practice, it establishes student activities within the health services, the evaluation of the policies, planning and management of the health services in activities of training and social communication in healthcare, linked to community organizations or diverse social entities. Thus, problems associated with the healthcare service can be identified, as well as the health conditions and life style of the population.

Keywords: Curricular Changes; Medical Training; Brazilian Healthcare System (SUS); PROMED

\section{INTRODUCTION}

In recent years, the need for fundamental changes in medical training [1] has become apparent, since it seems that doctors are not being trained to address the true needs of the population. This study demonstrates the importance of the health system of a country in the preparation of the future physician. In 1990, the Brazilian Law No. 8080 was proclaimed in order to regulate in the whole country the actions and health services, performed individually or together, either permanently or for any individual or legal entities, governmental or not. This law created the Brazilian National Healthcare System, which comprises a set of actions and health services provided by the governmental entities, public foundations and entities owned by the government in any of the powers of the Union, the states and the Municipalities, and the private enterprises may participate in a supplementary manner [2]. This change was directed toward the work of the Brazilian National Healthcare System (Sistema Único de Saúde-SUS), a public system maintained by the government for the whole Brazilian population dealing with primary, secondary and tertiary care.

In the past, the training was directed toward tertiary care. Thus, this was given greater value, incorporating technology, to the detriment of clinical experience [3].

The health sector has become a profitable market offering considerable business opportunities. However, the economic structure of Brazil does not allow everyone free access to care. In a study carried out on a population of 1000 inhabitants in Brazil, it was shown that in 1 month, 750 people will have health problems, of which only 250 will seek medical help. Of these, only 5 will require a specialist and 9 will be hospitalized [4]. Even so, most of the patients will be referred to secondary or tertiary care.

Against this scenario, an economic-financial crisis has occurred on the one hand and a social legitimacy crisis on the other. This has occurred in Brazil as well as in other countries [5] which follow the same model with an emphasis on the medical-industrial complex [6]. For this 
reason a change in the nature of medical training has become fundamental, in which, the doctor understands the public healthcare system and all of its variables.

By way of a wide social movement specifically in the health area called Movimento Sanitário, in 1998 a new constitution was approved which created the current Brazilian healthcare system (SUS) [7].

Later, the Ministry of Education and Culture (MEC) [1] and the Brazilian Medical Training Association (ABEM) detected that the doctor finished his training without the minimum of competence to address the requirements of the population [1,8], adopting a developed ethical-social posture. With the detection of this problem, the process of change [8] became obligatory.

In 1991, the National Inter-institution Committee for the Evaluation of Medical Training (CINAEM), assumed two objectives: to study the schools and construct a national movement able to democratically discuss teaching and the medical profession [8]. ABEM, Rede UNIDA, the Brazilian Association of Collective Health (ABRASCO) and the Federal Medical Council (CFM) put pressure on MEC to create Curricular Guidelines (CD). The CDs were approved in 2001, being directed toward SUS. However, in the medical schools the change is slow and faces many difficulties [7]. All of this movement had the support of the Ministry of Health (MS), which was prepared to work in partnership with MEC and the medical schools.

Since, in Brazil, the future doctors will develop much of their work in SUS [9].

In a join initiative the MS and MEC, created in 2002 the Program for the Promotion of Changes in Medical School Curricula (PROMED), with the objective of financially supporting medical schools, which developed and implemented curricular changes in the medicine courses toward the proposal based on the Curricular Guidelines.

In order to obtain this financial support, projects which would be subject to full and open competition were invited for submission [7,10], and the medical school would have to adapt voluntarily their teaching methods, knowledge production and services, and train doctors according to the curricular guidelines suitable for SUS $[7,10]$.

This has been directed toward the training of critical and creative professionals, able to assimilate the ideal of "learning to learn", generating mechanisms which contribute to the permanent reconstruction of their professional identity [11].

The guiding line of this restructuring has been the redefinition of the curricular structure, and the curricula are dependent on the planning of each medical school. These curricular changes are to be implemented along different paths between theory and practice, and must be planned and able to be carried out.
The curricula guidelines recommend the development of competences through real practice contextualized with the strategies and methodologies through these practices [10].

The axis of change established by the curricular guidelines has resulted in a broad internal mobilization in most of the medical schools and allowed that PROMED, offering the courses financial incentives, had an excellent reception. Nineteen received the financial support, since one of the schools did not submit the necessary documentation. The medical schools which were approved to receive PROMED are: Universidade Federal de Goiás (UFG), Fundação Universidade de Pernambuco (UPE), Universidade Federal de Pernambuco (UFPE), Universidade Federal do Ceará (UFC), Universidade Federal de Roraima (UFRR), Universidade Federal de São Paulo (UNIFESP), Universidade Federal de Minas Gerais (UFMG), Universidade Federal Fluminense (UFF), Pontifícia Universidade Católica de São Paulo (PUC-SP), Universidade Estadual de Campinas (UNICAMP), Universidade Estadual Paulista Júlio Mesquita Filho (UNESP), Faculdade de Medicina de Marília (FAMEMA), Universidade Estadual de Montes Claros (UNIMONTES), Universidade Federal de Juiz de Fora (UFJF), Fundação Educacional Serra dos Órgãos (FESO), Universidade Estadual de Londrina (UEL), Universidade Federal do Rio Grande do Sul (UFRGS), Pontifícia Universidade Católica do Rio Grande Sul (PUC-RS) and Universidade Federal de Santa Catarina (UFSC).

The following map shows the locations of the nineteen Brazilian medical schools which received PROMED funding (Figure 1):

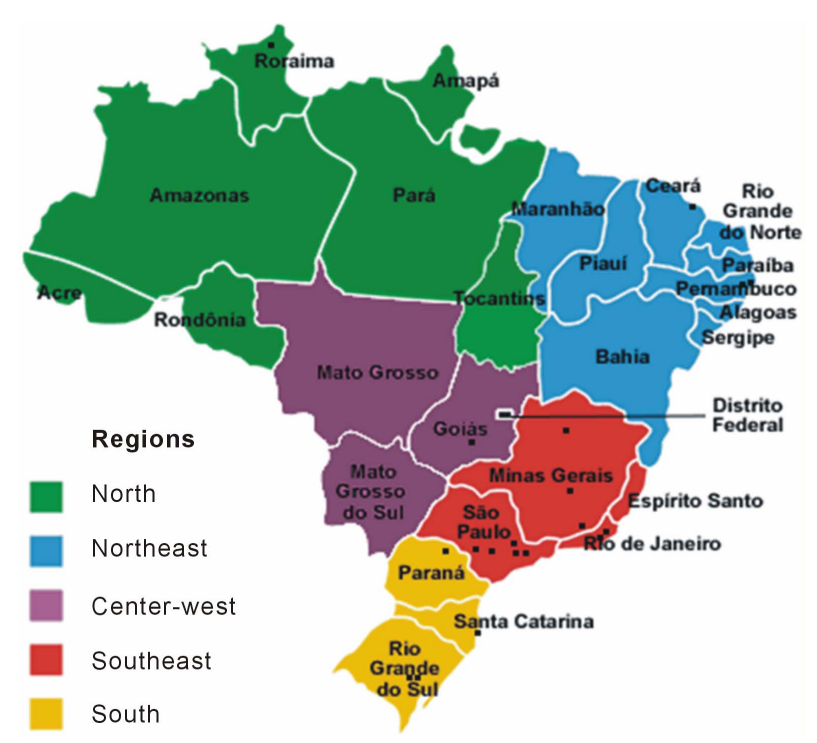

Figure 1. The geographical distribution of the Brazilian [12] medical schools which received PROMED. The geographical distribution of these medical schools around Brazil shows a greater concentration in the southeast region. 
This study aims, therefore, to verify the influence of PROMED on the interaction of the national public heath care system with the universities (SUS Network-University).

\section{METHODS}

Interviews were carried out with 19 coordinators of the medicine courses which received financial support from PROMED. These course coordinators are professors who receive a salary to hold the position of coordinator of the medicine course. The interviews were recorded, transcribed and analyzed by way of content analysis according to Laurence Bardin [13] and the methodology was based on the qualitative research of Cecília Minayo [14]. After the transcription of the interviews the organization of the information through a skim reading was carried out in order to obtain an overview of the statements. In a subsequent reading, the key words and significant parts were extracted and grouped according to the convergence and divergence of their meanings. From the reading, the location of the relevant structures was obtained, totalizing 1182, because they repeated and allowed an exhaustive reading of the originated texts. In order to classify them into analytical categories, some previously established, the general categories were reconstructed and the specific categories were constructed. The categories followed the same line laid out in the initially presented theoretical framework. The texts were organized and separated into sheets, according to the express comprehension of each theme.

All of the structures were grouped and then categorized into 9 themes: The Evaluation; The Curricular Guidelines and Practice; The Teaching Staff; Permanent Education: The need for Graduate courses-The Importance of Research; The School History; The Internship; Non-groupable, but important, structures; PROMED and the SUS Network-University interaction.

In this paper, the theme of the SUS Network-University interaction will be addressed, considering the interaction between SUS and the medical school. The theme has 5 categories: training of SUS professionals and teaching staff; research lines, partnership relations, internal problems and SUS strengthening.

Each school coordinator was identified by the letter $\mathrm{E}$ (Educator) and a subsequent number in order to preserve their identity.

\section{RESULTS AND DISCUSSION}

A basic prerequisite for the SUS Network-University interaction is to build relations of inter-institutional cooperation, that is, mechanisms of the co-management of the teaching-learning process and the production of health by universities, healthcare services and social or- ganizations [1].

\subsection{Training of SUS Professionals and the Teaching Staff}

One of the important aspects for the training of the future doctor, observed as a category in this theme, is the training of SUS professionals and the teaching staff, who must be prepared for the training of the "new" doctor, who will assume the work confronting the real population needs.

The medical practice to be taught by the professor and by the SUS professionals requires a pedagogically aware attitude which leads to their transformation and to that of the students who are under their responsibility [15]. For this reason, the teaching staff and the SUS professional must know how to teach and to be able to take on new pedagogical forms, considering a greater insertion of the student into the daily routine of SUS healthcare.

Thus, permanent education becomes an essential tool in the management of change, since it creates collective spaces, makes the work process an object of reflection and allows the professors to be producers and formulators committed to the change in progress [1].

E4: So we have to be aware of this political fragility, (...) it lies in the domain of a few people, thus we have to incorporate more actors, training people more is a great challenge which I have found in overcoming this barrier.

In the change process, it is of crucial importance to consider the differences within the institution and their dynamics, which includes an evaluation of the adhesion potential and the influence of each group of people mobilized by the challenges, strategies and mechanisms, to develop specific proposals of mobilization or neutralization [1].

Educator 4 signals the difficulty in encouraging the teaching staff and involves them in the curricular changes. It is through the courses and training that the teaching staff become aware of new methodologies and new practice scenarios, including, this time, SUS, and not only the private logic (privilege before the Public Health Reform), and this causes some discomfort to the teaching staff and consequently inhibits change.

E19: In the case of the network, the municipal manager, it is important that he is trained, is trained, to be a manager facing the reality of SUS.

The responses emphasized the possibility for the university to promote the permanent education of the health professionals and, to this end, a partnership for the training of students in the healthcare network is formed. One way to encourage this process is through Distance Learning, through offering places on graduate courses aimed at not affecting the ongoing service [10], for the healthcare 
professionals who have difficulty in physically attending classes, due to lack of time or means of locomotion.

To many professors, the interaction between teaching and the healthcare service represents the distancing of the medical school [16], therefore, on addressing the approximation with SUS, there are related issues (almost all structural) to be resolved.

\subsection{Lines of Research}

The training of the teaching staff was considered by the interviewees as being of crucial importance in the process of implementing and sustaining curricular innovations. In the medical area it is treated as a strategy to improving the teaching practices, being considered by some authors as an essential component in the process of curricular changes and their consolidation [16]. Besides this training of human resources, the lines of research which are developed require attention, since along with characterizing the teaching-service integration, they show the different styles of thinking and enable a meta-analysis to be carried out. These lines form part of the student learning process and allow its direction toward diverse types of learning. These researches must involve the needs of the service without succumbing to an academic strictness, which turns toward the real, the concrete. This takes place in the following manner:

E7: In general we have tried (...) to direct the lines of research toward the requirements of SUS trying to tune them within the demands of the Ministry of Health.

The work carried out in a partnership between the university and the services can occur both in the political and the operational spheres. This occurs when all parties are interested in the interaction. The active and collective participation of the teaching staff and service professionals, at various instances, broadens the commitments to quality, which increases the social relevance of these institutions [1].

The school-service partnership is important for the construction of a medical professional profile which will attend to the needs of the population. The curricular diversity allows the verification of the different ways to train all of the professionals, considering the curricular guidelines. The research shows and consolidates this.

\subsection{Relationships of the Partnership}

Another category found was the relationships of the partnership between the University and the Healthcare Network, since these will be the theoretical and practical learning scenarios of the students. The new curricular vision allows the breaking away from traditional paradigms, which are reviewed and represented in a structured way. These partnerships occur from the service, and the attendance of the population, up to the govern- mental sphere, as can be observed below:

E4: Challenge also that this curriculum, in order for it to be carried out fully, it assumes a considerable interaction with the healthcare system. In fact, we need to have in the healthcare service an ally (...), I think that the suitability of the training process regarding the needs of SUS is a guiding axis for most schools.

In the service network, it is possible to have a view of the patient as a whole, whether through the doctor-patient relationship or through the interaction which the patient has with the community, allowing an approach which involves also a better adherence to the treatment [17]. This is one of the important points of the partnership, the network and the university working together in the medical training.

E11: If you have committed people it flows more easily, more rapidly, less, less chaotic and in the city council it is the same thing.

For this collaboration to be guaranteed, the relevant tools are required which allow high level teaching, such as an increase in the number of places for teaching staff, tutors and network professionals.

E1: Communication between the city council and the university in this teaching-service integration is already happening, but with some difficulties due to a lack of this network professional (...).

However, with existing differences, academia and the healthcare services often have divergent aims [18] and thus conflicts arise.

The university, the population and the services do not show homogeneity in the forms of comprehension, for example, in the inner workings of each one there are groups with distinct interests which perform contradictory and distinct roles which are changeable over time. It is important to recognize this heterogeneity and prepare strategically how to deal with this. Furthermore, there is an important asymmetry of power between these partners. Thus, it is necessary to be previously disposed to an agreement, since the conflicts to determine the path to follow are intense [1].

\subsection{Internal Problems}

It can be verified that there are many internal problems which are highlighted during the construction of the new curriculum. Despite this category having similarities with the previous one, it was characterized in a different way by its particularities.

E5: We have helped the others to discover that (...) this whole process has brought us a lot of difficulty, a lot of resistance, a lot of internal fighting, but lots and lots of happiness.

The proposals for change encounter resistance to their application. Although formulated over 30 years ago, the 
proposals for the teaching-services integration and the changes to the medical curriculum aiming at the integration of subjects has not been successful, since there are many opposed to it, arguing that the research and development of medical science would be harmed by the diverting of medical professors' time and energy toward the service, the student not then being exposed to the most advanced ideas [16].

E14: Another side to primary healthcare we, even having professors employed, we have the difficulty of the involvement of the network, of the healthcare network in the receiving of the students, in such a way as to interact with the guidelines of our curriculum.

Many conflicts are the result of problems and difficulties of network-university integration, in which the complaints originate from the fact that the university is inserted in the network without considering the work of the healthcare professionals who act there, nor the marked difference between the logic of the service organization, which has been for a long time centered on the productivity of technical-operating procedures and the logic of the work of the training institution, which is very centered on the production of theoretical knowledge and methodologies in the pedagogic and specific fields [18].

As can be observed, the integration between the university and the network is considered by the interviewees to be a determining factor in the process. The integration of the teaching staff with the professionals and the tuning of the teaching-service partnership are essential.

\subsection{Strengthening of SUS}

There is a concern on the part of the coordinators with the strengthening of SUS as a guiding axis for the training of doctors, allowing that the professional attends the real needs of the population. This was not the central focus before PROMED.

E9: The PROMED proposal, it will update this for the current health reality, which is configured from the judicial point of view, with SUS, with the Constitution of 88, and the operational point with SUS. From the judicial point of view with the Constitution and with the two organic health laws and from the operational point of view with SUS, with all of the known characteristics of SUS. Universality with healthcare guaranteed to all, guaranteed by economic and social policies, it is just that the economic ones are not guaranteeing the social ones, this is an important aspect. But it is part of the utopia of our era and all those who live today. It is important that we maintain this.

The consolidation and strengthening of SUS in the country allows collective healthcare to be guaranteed for the majority of the population. Collective healthcare is of extreme importance as part of the medical training proc- ess and it was responsible for a notable role in the changes, both in the curricular guidelines and, particularly, in PROMED.

Teaching in SUS, besides inducing a greater contact with the everyday lives of the people, establishes activities for the student in epidemiological practices in the healthcare services, evaluation of policies, planning and management of healthcare services in health activities in education and social communication, linked to diverse community organizations or social entities, according to the practical scenarios defined by the schools, identifying, thus, the problems in the healthcare services, as well as the health conditions and life style of the population [10].

\section{CONCLUSIONS}

The principles of SUS are included within the medical teaching and the curricular guidelines directed toward the change.

There is an awareness of the need for the SUS network-University cooperation. It is constitutional that SUS acts as a training field for the training of professionals in the healthcare area, however, there are all types of difficulties to be overcome before this can materialize. It is understood that the difficulties are many, among them the harmonious approximation of the service network with the university, the insufficient funding, the emphasis of most professors on hospital and specialization teaching, the lack of monitoring and permanent application of an evaluation program regarding the curricular reform.

The training of healthcare professionals, respecting the national guidelines approved by MEC, must consider the fast rhythm of knowledge evolution, the change in the work process in healthcare, the transformation in the demographic and epidemiological aspects, taking as the perspective the balance between technical excellence and social relevance. It is also necessary to reorient the research carried out in the healthcare area, the investigation of community needs, the organization, medical training, the funding of healthcare services, the experimentation of new models of intervention, the evaluation of the incorporation of new technologies and the development of indicators which allow a better estimation of the resolvability of healthcare issues.

All of these measures assume the effective construction of the teaching-services integration, which involves basic and other levels of healthcare, taking full advantage of the installed capacity of the network of services, complemented by the use of University Hospitals and/or specialized service units dependent on the teaching institutions, functionally integrated with SUS. The reciprocal interaction between the managers of the Educational Systems and SUS will allow the creation of real condi- 
tions in order to benefit from both systems with better technical quality in healthcare and in the teachinglearning process.

In the movement for change in the training of health professionals in Brazil, the PROMED program was understood as being strong enough to trigger other processes. Nevertheless, it faces difficulties, one of which is that it failed to predict the need for monitoring and the permanent application of an evaluation program [19].

\section{REFERENCES}

[1] Feuerwerker, L.C. (2004) Gestão dos processos de mudanças na graduação em medicina. In: Marins, J.J., Rego, S., Lampert, J.B. and Araújo, J.G.C., Eds., Educação Médica em Transformação: Instrumentos para a Construção de Novas Realidades, Hucitec, São Paulo.

[2] Brasil Ministério da Saúde, Secretaria de Gestão Estratégica e Participativa (2006) A construção do SUS: Histórias da reforma sanitária e do processo participativo /ministério da saúde, secretaria de gestão estratégica e participativa. Ministério da Saúde, Brasília.

[3] Bulcão, L.G., El-Kareh, A.C. and Sayd, J.D. (2007) Ciência e ensino médico no Brasil (1930-1950). Hist. cienc. Saúde-Manguinhos, 14, 467-489.

[4] Takeda, S. (2004) A organização de serviços de atenção primária à saúde. In: Duncan, B., Ed., Medicina Ambulatorial: Condutas de Atenção Primária Baseada em Evidências, 3rd Edintion, Artmed, Porto Alegre, 76-87.

[5] Almeida, M.J. (2001) A educação médica e as atuais propostas de mudança: Alguns antecedentes históricos. Revista Brasileira de Educação Médica, 25, 42-52.

[6] Da Ros, M.A. (2004) A ideologia nos cursos de medicina. In: Educação Médica em Transformação. Instrumentos para Construção de Novas Realidades. Editora Hucitec, São Paulo.

[7] CREMESP —Conselho Regional de Medicina do Estado de São Paulo (2003) Por que somos contra a abertura de novos cursos de medicina. Associação paulista de medicina. Federação dos Médicos do Estado de São Paulo.
[8] Peixinho, A.L. (2001) Educação médica-o desafio de sua transformação. Universidade Federal da Bahia, Salvador, 249.

[9] Desculpe, mas esta página não existe... (2005). http://www.redeunida.org.br/boletim/36/pg1.asp

[10] PROMED (2002) Programa de incentivo a mudanças curriculares nos cursos de medicina. Uma nova Escola Médica para um novo Sistema de Saúde. Secretaria de Políticas de Saúde-Ministério da Saúde. Secretaria de Educação Superior-Ministério da Educação.

[11] Teixeira, C.F. (2004) Ensino da saúde coletiva na graduação. Cadernos ABEM, 1, 20-22.

[12] http://www.brasilrepublica.com/mapa.htm

[13] Bardin, L. (1977) Análise de conteúdo. Edições, São Paulo.

[14] Minayom, M.C.S. (1994) O desafio do conhecimentoPesquisa qualitativa em saúde. 3rd Edition, Hucitec, São Paulo.

[15] Schimidt, L.M., Ribas, M.H. and Carvalho, M.A. (2003) A prática pedagógica como fonte de conhecimento. In: $O$ Trabalho Docente Teoria \& Prática. Queluz Ana Gracinda, Alonso Myrtes (orgs). Pineira Thomson Learning, São Paulo, 19-33.

[16] Lima, G.Z., Almeida, H.G.G., Filho, O.F.F., Linhares, R.E.C., Oberdiek, H.I. and Colus, I.M.S. (2003) Aprendizagem baseada em problemas (ABP): Construindo a capacitação em Londrina. Revista Brasileira de Educação Médica, 27, 5-1

[17] Albuquerque, V. dos S., et al. (2008) A Integração Ensinoserviço no contexto dos processos de mudança na formação superior dos Profissionais da Saúde. Revista Brasileira de Educação Médica, 32, 356-362.

[18] Silva, C.A.J. (2004) Interação escola médica-serviços. Cadernos ABEM, 1, 9-11.

[19] Souza, P.A., Zeferino, A.M.B. and Ros, M.A. (2008) Changes in medicine course curricula in Brazil encouraged by the Program for the Promotion of Medical School Curricula (PROMED). BMC Medical Education, 8, 54. doi:10.1186/1472-6920-8-54 